Y. ZHU, T. CAO, C. CAO*, J. LUO, W. CHEN, L. ZHENG, J. DONG, J. ZHANG, Y. HAN, Z. LI, C. CHEN, Q. PENG, D. WANG, Y. LI* (TSINGHUA UNIVERSITY, BEIJING, BEIJING INSTITUTE OF TECHNOLOGY, INSTITUTE OF HIGH ENERGY PHYSICS (CAS), BEJING, AND TIANJIN UNIVERSITY OF TECHNOLOGY, P. R. OF CHINA)

One-Pot Pyrolysis to N-Doped Graphene with High-Density Pt Single Atomic Sites as Heterogeneous Catalyst for Alkene Hydrosilylation

ACS Catal. 2018, 8, 10004-10011.

\section{Hydrosilylation of Alkenes Catalyzed by Platinum on N-Doped Graphene}

\section{Category}

Polymer-Supported

Synthesis

Key words

N-doped graphene

platinum catalysis

hydrosilylation

alkenes

nanostructures $\begin{aligned} & \text { EDTA-Pt } \\ & \text { complex }\end{aligned}+\mathrm{Na}_{2} \mathrm{CO}_{3} \underset{850^{\circ} \mathrm{C}, 1 \mathrm{~h}}{\stackrel{\mathrm{HCl}}{\longrightarrow}} \underset{-\mathrm{Na}_{2} \mathrm{CO}_{3}}{\longrightarrow} \quad$ Pt-ISA/NG

$\mathrm{EDTA}=$ ethylenediaminetetraacetic acid

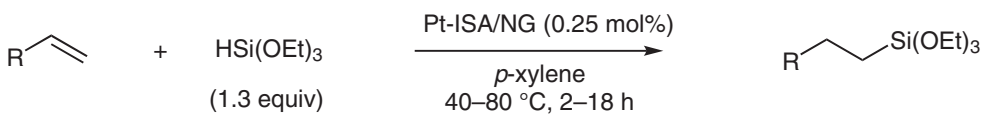

Results:

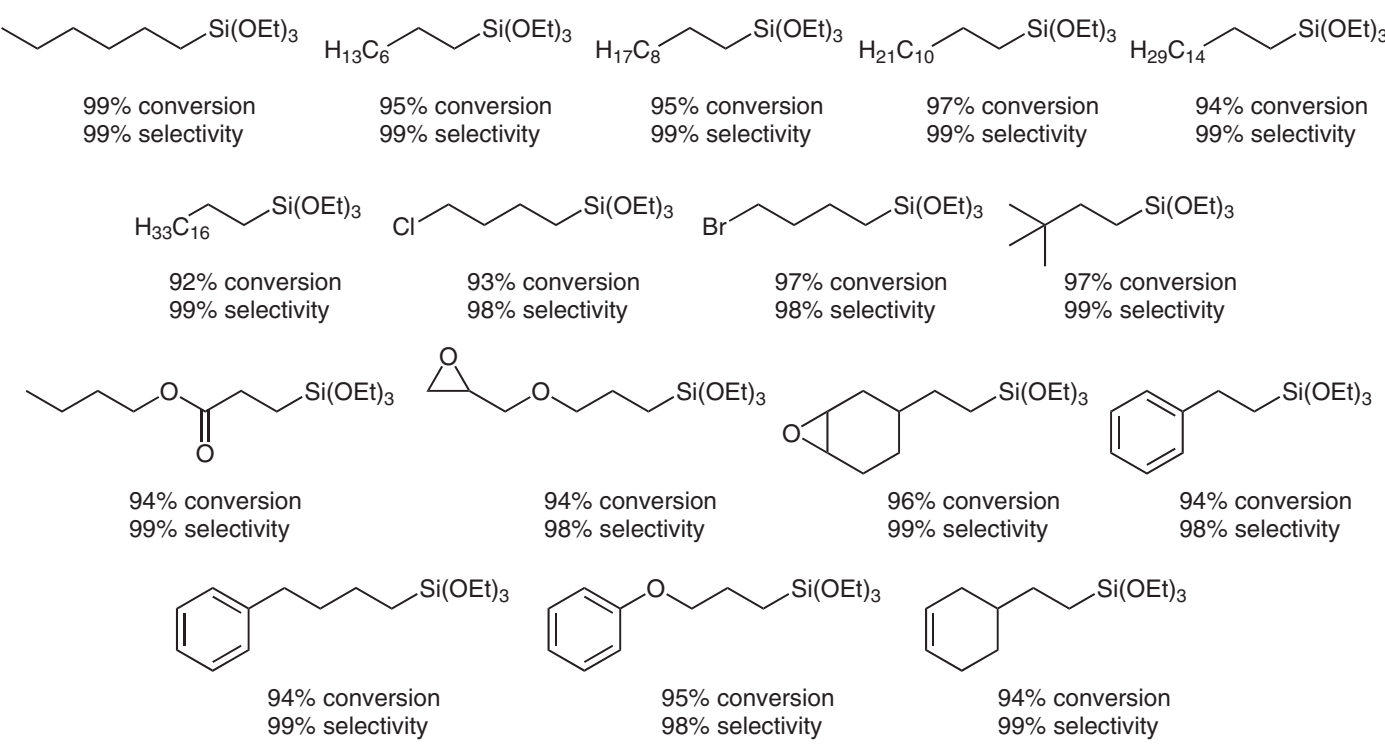

$S(1)$

Significance: Single-atom platinum catalyst supported on N-doped graphene (Pt-ISA/NG) was prepared by heating a mixture of an EDTA-Pt complex and $\mathrm{Na}_{2} \mathrm{CO}_{3}$ at $850{ }^{\circ} \mathrm{C}$ for one hour, followed by removal of the $\mathrm{Na}_{2} \mathrm{CO}_{3}$ with dilute $\mathrm{HCl}$ (eq. 1). Pt-ISA/ $\mathrm{NG}$ catalyzed the hydrosilylation of alkenes with triethoxysilane to give the corresponding silylated alkanes in $\leq 99 \%$ conversion and $\leq 99 \%$ selectivity (eq. 2).
Comment: The authors have previously reported the preparation of the EDTA-Pt complex (Nano Res. $2018,11,3088$ ). In the hydrosilylation of octan-1one with triethoxysilane, Pt-ISA/NG was reused four times without significant loss of its catalytic activity. TEM, EDX, HAADF-STEM, and EXAFS studies on the recovered Pt-ISA/NG indicated that the structural and electronic integrity of Pt-ISA/NG was maintained under the reaction conditions. 